\title{
EFFECTS OF SALINE-ALKALI MIXED STRESS ON THE GROWTH AND PHYSIOLOGICAL CHARACTERISTICS OF GIANT JUNCAO (PENNISETUM GIGANTEUM Z. X. LIN)
}

\author{
MA, Y. X. ${ }^{1}-$ LI, G. T. ${ }^{*}{ }^{*}$ WANG, G. H. ${ }^{1}-$ LIANG, T. Y. ${ }^{2}-$ YAN, J. Q. Z. ${ }^{1}-$ LI, J. J. ${ }^{1}$ \\ ${ }^{1}$ College of Desert Control Science and Engineering, Inner Mongolia Agricultural University, \\ Hohhot 010018, China \\ ${ }^{2}$ School of Biological Science and Technology, Baotou Teachers' College, Baotou 014030, China \\ ${ }^{*}$ Corresponding author \\ e-mail: 13848817183@163.com
}

(Received 21 $1^{\text {st }}$ May 2020; accepted $17^{\text {th }}$ Sep 2020)

\begin{abstract}
In this paper, a pot experiment was conducted to simulate different degrees of saline-alkali stress to explore the response mechanism of Pennisetum giganteum Z. X. Lin to salt stress concerning its growth and physiological characteristics. The results showed that: (1) the growth of plant height decreased obviously with the increase of salt solution concentration; (2) with the increase of concentration, MDA content accumulated intermittently, $P$. giganteum reduced oxidative damage and maintained normal plant physiological metabolism through the complementary action of antioxidant enzymes SOD and CAT; (3) when the concentration of mixed salt solution was low, all osmotic regulatory substances accumulated slowly, and with the continuous increase of concentration, free proline content increased rapidly, which played a leading role in the process of plant osmotic regulation to ensure its physiological activities; (4) under mixed saline-alkali stress, the roots and stems of $P$. giganteum absorbed most of the $\mathrm{Na}^{+}$, and transported $\mathrm{K}^{+}$to the leaves at the same time.
\end{abstract}

Keywords: Pennisetum giganteum Z. X. Lin, saline-alkali stress, growth, antioxidant enzyme, osmotic adjustment, ion response

\section{Introduction}

Soil salinization is a problem that concerns the whole world. It has great influence on agriculture, forestry and other aspects (Bless et al., 2018). In the world, salinization soil accounts for more than half of the land, and there are different types of salinization soil in various countries. The area of saline alkali land in China reaches up to $1.0 \times 10^{8} \mathrm{hm}^{2}$ (Zhang et al., 2020). Soil salinization is not conducive to the absorption of nutrients by crops and seriously interferes with and restricts the growth of plants, which undoubtedly causes serious harm to the current resources and ecology. It is precisely because of the worsening of soil that the cultivated land keeps decreasing, so it is urgent to develop agriculture in saline alkali soil, and it is of great significance to improve the ecological environment for a long time (Singh, 2015; Liu, 2018). Most studies have found that plants can exhibit a variety of regulatory mechanisms under external stress, including detoxification effects, the absorption and balance of mineral elements, and the regulation of antioxidant systems (Ma et al., 2015; Zhu et al., 2020). The study of Song et al. (2017) show that the accumulation of proline, sugars and organic acids which make positive impacts in Alfalfa (Medicago sativa L.)'s regulation of cell osmotic pressure, $\mathrm{pH}$ balance and reactive oxygen species (ROS) removal under stress. Jia et al. (2017) reported Hall Crabapple (Malus halliana Koehne) responded to salt stress (SS), alkali stress (AS) and saline-alkali stress (MAS) by reducing leaf water content (WC), stomatal conductance $(G \mathrm{~s})$ and intercellular $\mathrm{CO}_{2}$ concentration $(\mathrm{Ci})$, increasing water 
use efficiency (WUE) and accumulating osmolytes, and in MAS, SS and AS had good synergistic effect.

Previous research has shown that the continuous expansion of saline alkali soil area and saline alkali stress will cause different degrees of harm to plant growth physiology, which has caused great trouble to the introduction and promotion of Pennisetum giganteum Z. X. Lin, a fine grass species (Hayat et al., 2020). However, at present, the researches on $P$. giganteum mainly focus on drought resistance and cold resistance, and there are few reports on the response of $P$. giganteum to saline-alkali stress. In this study, the mixed salt solution was applied to simulate the different degree of salinealkali of the seedlings of $P$. giganteum, the growth physiological indexes of the seedlings were measured under various concentrations, and the response of the seedlings of $P$. giganteum to saline-alkali stress was studied, in order to reveal its physiological defense mechanism under saline-alkali stress, further master its physiological growth status in the adversity, and promote the development and promotion of $P$. giganteum in saline-alkali areas provide theoretical basis and reference.

\section{Experiments and methods}

\section{Test materials}

The test $P$. giganteum was introduced from Fujian Province of southeastern China and planted in the greenhouse of Inner Mongolia Agricultural University, Inner Mongolia Autonomous Region, China. The buds with the same growth were planted in the flowerpot to raise seedlings, and the seedlings with the same growth were selected for the test.

\section{Test method}

Based on the main components of saline-alkali soil and the previous studies (Ashraf and Akram, 2009; Bui, 2013; Mambetale et al., 2017), the soil salinization types in the arid and semi-desert steppe salinization area of Inner Mongolia Plateau were artificially simulated. In this paper, $\mathrm{NaCl}, \mathrm{Na}_{2} \mathrm{SO}_{4}, \mathrm{NaHCO}_{3}$ and $\mathrm{Na}_{2} \mathrm{CO}_{3}$ were mixed according to different molar ratio to simulate the salt damage of the saline-alkali mixed stress on the $P$. giganteum. According to the increasing mode of the alkali salt content, the ratio A, B, $\mathrm{C}, \mathrm{D}, \mathrm{E}$ was set in each of the five mixed treatment groups (Table 1), the tolerance threshold of single salt of $P$. giganteum was set with five gradients, namely 30 $\mathrm{mmol} \cdot \mathrm{L}^{-1}, 60 \mathrm{mmol} \cdot \mathrm{L}^{-1}, 90 \mathrm{mmol} \cdot \mathrm{L}^{-1}, 120 \mathrm{mmol} \cdot \mathrm{L}^{-1}$ and $180 \mathrm{mmol} \cdot \mathrm{L}^{-1}$.

Table 1. Salt composition of each treatment group

\begin{tabular}{c|c}
\hline Treatment group & Proportion of salt and alkali in treatment group \\
\hline $\mathrm{A}$ & $\mathrm{NaCl}: \mathrm{Na}_{2} \mathrm{SO}_{4}: \mathrm{NaHCO}_{3}: \mathrm{Na}_{2} \mathrm{CO}_{3}=1: 1: 0: 0$ \\
$\mathrm{~B}$ & $\mathrm{NaCl}: \mathrm{Na}_{2} \mathrm{SO}_{4}: \mathrm{NaHCO}_{3}: \mathrm{Na}_{2} \mathrm{CO}_{3}=1: 2: 1: 0$ \\
$\mathrm{C}$ & $\mathrm{NaCl}: \mathrm{Na}_{2} \mathrm{SO}_{4}: \mathrm{NaHCO}_{3}: \mathrm{Na}_{2} \mathrm{CO}_{3}=1: 9: 9: 1$ \\
$\mathrm{D}$ & $\mathrm{NaCl}: \mathrm{Na}_{2} \mathrm{SO}_{4}: \mathrm{NaHCO}_{3}: \mathrm{Na}_{2} \mathrm{CO}_{3}=1: 1: 1: 1$ \\
$\mathrm{E}$ & $\mathrm{NaCl}: \mathrm{Na}_{2} \mathrm{SO}_{4}: \mathrm{NaHCO}_{3}: \mathrm{Na}_{2} \mathrm{CO}_{3}=9: 1: 1: 9$ \\
\hline
\end{tabular}

\section{Simulated stress of mixed salt}

When the seedlings grow to three pairs of leaves in the flowerpot, 80 seedlings with basically the same growth potential are selected and randomly allocated into 26 groups. 
Three repetitions are set in each treatment group. One group is selected as CK and distilled water with $\mathrm{pH}$ of 6.8 is irrigated in the treatment project. The stress treatment was conducted from 8:00 to 9:00 in the morning. Each pot was irrigated with $200 \mathrm{ml}$ of the corresponding mixed solution prepared in advance, which was stressed for 7 days, and the corresponding weight was recorded. The water content of potted soil was controlled by weighing method. From the second day of stress, each flowerpot was weighed at 9:00 a.m. every day, and compared with the previously recorded data, the water lost by evaporation in the flowerpot was supplemented in time. At the same time, in order to prevent the loss of mixed salt solution, a plastic tray is placed at the bottom of each flowerpot, and the solution in the tray is timely poured back into the flowerpot every day. After 7 days, the functional leaves of the same part in different treatment groups were taken back to the laboratory for physiological index determination under low temperature environment.

\section{Physiological indexes and measurement methods}

The growth of plant height was measured by the method of drying; the activity of malondialdehyde (MDA) and catalase (CAT) was measured as described by Liang et al. (2015) and Maia et al. (2010); superoxide dismutase (SOD) activity was determined by the nitroblue tetrazoliun (NBT) method (Yang et al., 2013); soluble sugar content by anthrone colorimetry, free proline content by acid ninhydrin colorimetry, soluble protein content by coomassie brilliant blue G-250 (Zou, 2000).

\section{Determination of the $\mathrm{Na}^{+}$and $\mathrm{K}^{+}$in root, stem and leaf}

After 22 days of stress treatment, three seedlings were taken according to different proportions of mixed salt. After washing, the roots, stems and leaves were separated and killed in an oven at $105^{\circ} \mathrm{C}$ for 10 minutes, then the temperature was adjusted to $80{ }^{\circ} \mathrm{C}$ to dry until constant weight. The dried root, stem and leaf samples were thoroughly crushed and passed through $1 \mathrm{~mm}$ sieve, $0.2 \mathrm{~g}$ was added to nitrifying solution $(10 \mathrm{ml}$ concentrated nitric acid, $2 \mathrm{ml} 60 \%$ trichloroacetic acid, $1 \mathrm{ml}$ concentrated sulfuric acid) and boiled water bath at $90^{\circ} \mathrm{C}$ for $60 \mathrm{~min}$. After cooling, the $1 \mathrm{ml}$ mixture was taken and fixed in a $50 \mathrm{ml}$ capacity flask, and the contents of the $\mathrm{Na}^{+}$and $\mathrm{K}^{+}$in roots, stems and leaves under different saline-alkali ratios and concentrations were determined by flame spectrophotometer (TAS-990, Purkinje General, Beijing, China).

\section{Data processing}

Data were analysed using least significant difference test $\left(\mathrm{LSD}_{0.05}\right)$ by using IBM SPSS Statistics v20. Excel 2007 was used for mapping, and the data was represented by three times of repeated mean value and standard error (SE).

\section{Results and analysis}

\section{Effects of mixed saline-alkali stress on growth indicators}

Saline-alkali stress has a certain effect on the apparent morphology of plant growth (Fig. 1). Figure 2 shows that in the treatment groups with different proportion of A, B, $\mathrm{C}, \mathrm{D}$ and $\mathrm{E}$, with the increase of salt concentration, the growth of plant height of $P$. giganteum shows a downward trend, but there are great differences between the various treatment groups. In the pure salt solution and the low alkali salt proportion of 
$\mathrm{A}$ and $\mathrm{B}$, the downward trend is relatively slow, among which, the trends of the two groups with concentration of $30 \mathrm{mmol} \cdot \mathrm{L}^{-1}$ and $60 \mathrm{mmol} \cdot \mathrm{L}^{-1}$ are basically the same. However, there was no significant difference between group $\mathrm{B}$ at $30 \mathrm{mmol} \cdot \mathrm{L}^{-1}$ and $\mathrm{CK}$. In group $\mathrm{B}$, when the concentration increased to $180 \mathrm{mmol} \cdot \mathrm{L}^{-1}$ the plant height growth decreased to the lowest value, 75.08\% lower than CK. In the A, C, D, E treatment groups, the plant height growth of different concentrations of salt solution in various treatment groups were significantly lower than $\mathrm{CK}$, and reached the minimum value at $180 \mathrm{mmol} \cdot \mathrm{L}^{-1}$, which were $64.01 \%, 68.22 \%, 61.68 \%$ and $62.62 \%$ lower than $\mathrm{CK}$, respectively. The above results showed that, in the process of stress, the overall trend of decline, in the $\mathrm{pH}$ value of 8.22 , and the concentration of no more than $30 \mathrm{mmol} \cdot \mathrm{L}^{-1} \mathrm{~B}$ treatment group and CK no significant difference, more suitable for the growth of $P$. giganteum, and other treatments to varying degrees inhibited its growth.
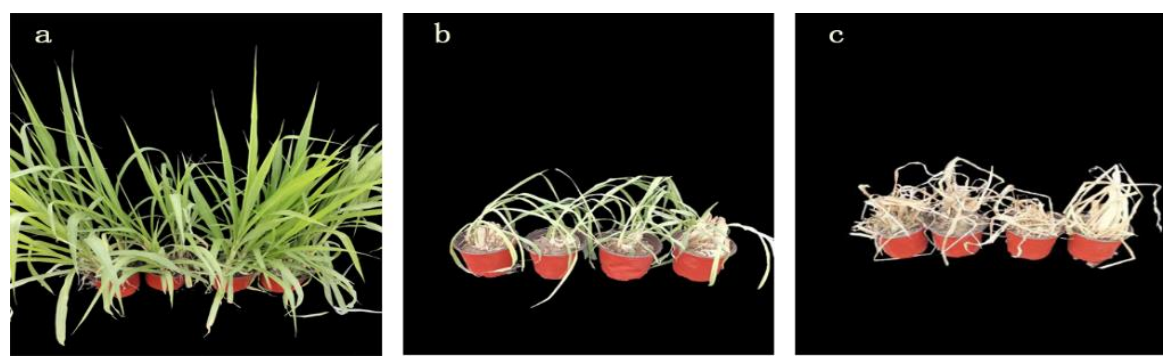

Figure 1. Influence of saline-alkali stress on the growth of P. giganteum: a) normal, b) Wilting under stress, and c) Death under stress

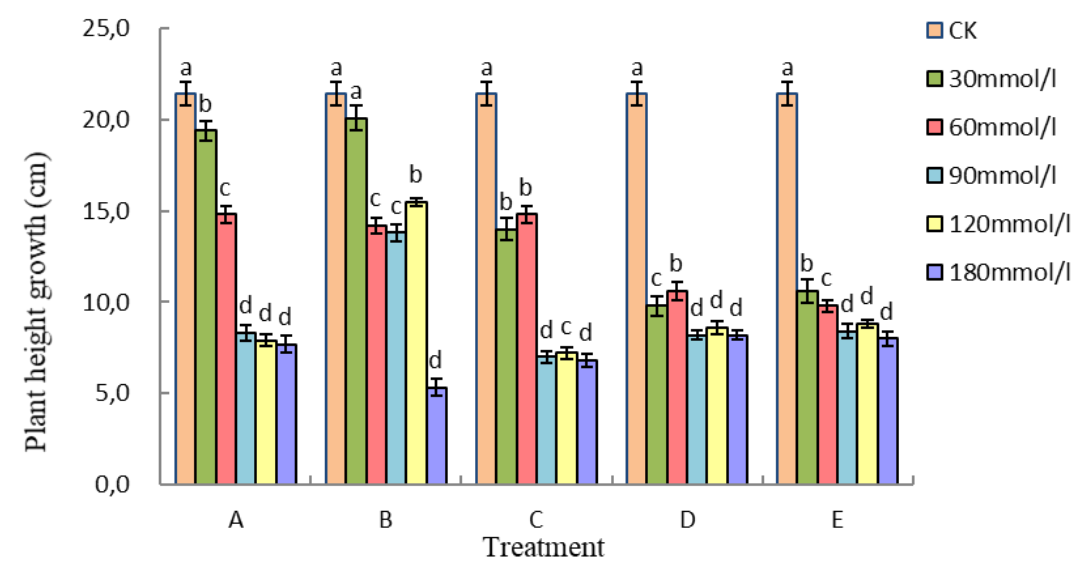

Figure 2. Changes in plant height growth in P. giganteum seedlings under under saline-alkali stress. Different treatments: A) $\left.\mathrm{NaCl}: \mathrm{Na}_{2} \mathrm{SO}_{4}: \mathrm{NaHCO}_{3}: \mathrm{Na}_{2} \mathrm{CO}_{3}=1: 1: 0: 0, \mathrm{~B}\right) \mathrm{NaCl}$ :

$\left.\left.\mathrm{Na}_{2} \mathrm{SO}_{4}: \mathrm{NaHCO}_{3}: \mathrm{Na}_{2} \mathrm{CO}_{3}=1: 2: 1: 0, \mathrm{C}\right) \mathrm{NaCl}: \mathrm{Na}_{2} \mathrm{SO}_{4}: \mathrm{NaHCO}_{3}: \mathrm{Na}_{2} \mathrm{CO}_{3}=1: 9: 9: 1, \mathrm{D}\right)$ $\mathrm{NaCl}: \mathrm{Na}_{2} \mathrm{SO}_{4}: \mathrm{NaHCO}_{3}: \mathrm{Na}_{2} \mathrm{CO}_{3}=1: 1: 1: 1$, E) $\mathrm{NaCl}: \mathrm{Na}_{2} \mathrm{SO}_{4}: \mathrm{NaHCO}_{3}: \mathrm{Na}_{2} \mathrm{CO}_{3}=9: 1: 1: 9$.

Columns with different letters indicate significant difference $(P \leq 0.05)$ among various concentrations in the same treatment based on least significant difference test (LSD). The same as below

\section{Effects of mixed saline-alkali stress on physiological indexes}

According to the data in Figure 3, the MDA content in the leaves of P. giganteum showed an increasing trend with the increase of salt concentration in each mixed salt 
configuration group, and the MDA content in the leaves of $P$. giganteum under different proportions was higher than that of the control group, most of which were significantly higher than that of the control group. Both groups $C$ and $D$ reached the peak value of $30 \mathrm{mmol} \cdot \mathrm{L}^{-1}, 2.09$ times and 2.19 times higher than the control, while groups $\mathrm{A}$ and $\mathrm{E}$ reached the peak value of $180 \mathrm{mmol} \cdot \mathrm{L}^{-1}$ and group $B$ reached the peak value of $120 \mathrm{mmol} \cdot \mathrm{L}^{-1}, 3.10$ times, 2.46 times and 3.07 times higher than the control. From the $\mathrm{pH}$ value, when the salt concentration reached the maximum, the MDA content in the leaves of $P$. giganteum group A, which was all neutral salt, and group E, which had A higher ratio of alkaline salt, suddenly increased to the peak, and was significantly higher than that of other treatment groups at the same concentration. The above results showed that under the treatment of high salt concentration and low $\mathrm{pH}(6.08)$ and high salt concentration and high $\mathrm{pH}(10.55)$, the peroxidation degree of the leaves of the $P$. giganteum increased, the growth and development of the plants were seriously damaged, and wilting and death appeared.

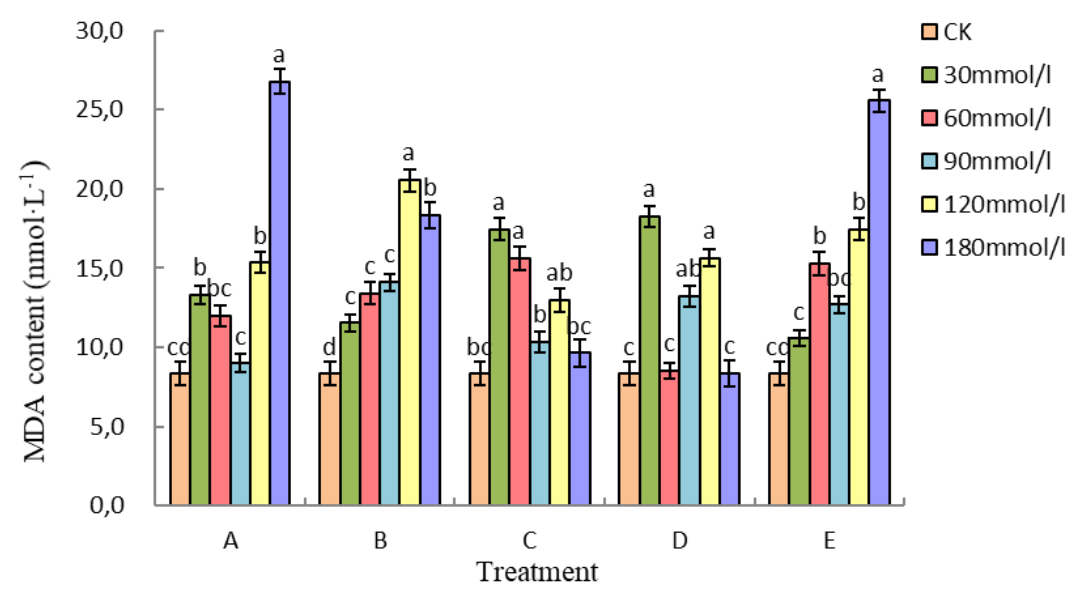

Figure 3. Changes in MDA content in P. giganteum seedlings under saline-alkali stress

It can be seen from Figure 4, compared with the control, catalase activity in the leaves of the $P$. giganteum in the five treatment groups $\mathrm{A}, \mathrm{B}, \mathrm{C}, \mathrm{D}$, and $\mathrm{E}$ all increased with the increase of the mixed salt concentration, but the difference was different. The proportion of the mixed salt is very different from the trend. Among them, in the treatment group A containing pure salt, the catalase activity of $P$. giganteum leaves increased numerically with the increase of the salt concentration, but there was no significant difference between the two groups, and the change was relatively gentle. The catalase activity in leaves of $\mathrm{B}$ and $\mathrm{C}$ treated groups with higher $\mathrm{Na}_{2} \mathrm{SO}_{4}$ content showed a law of first increase and then decrease with the increase of the concentration of the mixed solution, which was significantly different from the control. The highest peak of peroxidase activity in the B treatment group appeared at $60 \mathrm{mmol} \cdot \mathrm{L}^{-1}$, which was an increase of 1.28 times compared to the control; the maximum value of the peroxidase activity in the $\mathrm{C}$ treatment group appeared at $120 \mathrm{mmol} \cdot \mathrm{L}^{-1}$, compared with the control increased by 1.24 times, and the catalase activity under the mixed salt concentration stress in the $C$ treatment group was always maintained at a relatively stable level with a small change. The catalase activity of the leaves of $P$. giganteum and E treatment groups increased with the increase of the salt concentration. The catalase activity of the leaves of caterpillar fungus was relatively consistent. Both of them increased significantly with the increase of the salt concentration. 
The highest peak appeared at $180 \mathrm{mmol} \cdot \mathrm{L}^{-1}$, which increased by 1.26 times and 1.24 times compared with the control, respectively.

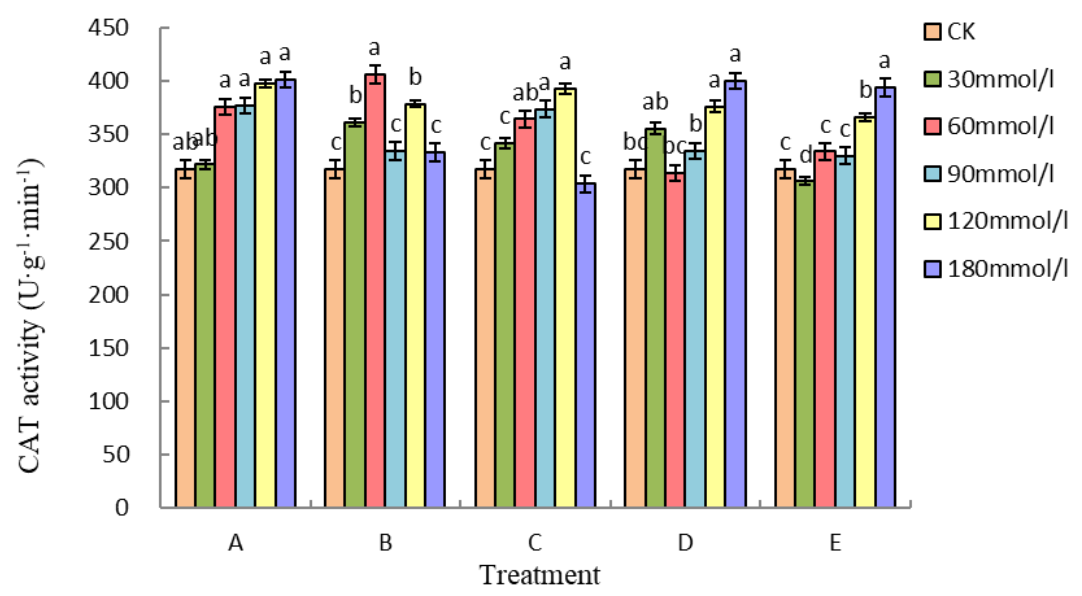

Figure 4. Changes in CAT activity in P. giganteum seedlings under saline-alkali stress

Figure 5 shows that the variation trend of superoxide dismutase activity in the leaves of $P$. giganteum with different saline-alkali ratio treatment groups is decreased in the context of gradually increasing mixed salt concentration. Among them, in the two extreme ratios of $\mathrm{A}$ and $\mathrm{E}$, superoxide dismutase activity showed two extreme values, which first decreased, then increased and then decreased. At the same time, superoxide dismutase activity reached the maximum value when the mixture concentration was $120 \mathrm{mmol} \cdot \mathrm{L}^{-1}, 1.17$ times and 1.03 times of the control, respectively. Treatment group A reached the minimum value at $90 \mathrm{mmol} \cdot \mathrm{L}^{-1}$, which was $9.34 \%$ lower than the control group, while treatment group $\mathrm{E}$ reached the minimum value at $60 \mathrm{mmol} \cdot \mathrm{L}^{-1}$, which was $44.08 \%$ lower than the control group B and C treatment group fluctuation is large, and the change process are complex, all showed down - up - then - rising change rule, and tendency in $90 \mathrm{mmol} \cdot \mathrm{L}^{-1}$ reach the peak of its active, comparison of 1.25 times and 1.09 times, respectively, but in A treatment is pure salt group, there was A significant difference compared with the peak, and join the alkali content of peak B treatment group compared with no significant difference. Superoxide dismutase activity in the environment of the D-treated group was in a downward trend, and there was no significant difference between the two groups. Moreover, the activity reached the minimum value at $120 \mathrm{mmol} \cdot \mathrm{L}^{-1}$, which was $35.23 \%$ lower than that of the control group.

\section{Effects of mixed saline-alkali stress on osmotic regulators}

Figure 6 shows that the soluble sugar content increases intermittently in the context of increasing concentration in different ratio treatments. In the treatment group A, the soluble sugar content was significantly lower than that of the control only in the environment with A concentration of $60 \mathrm{mmol} \cdot \mathrm{L}^{-1}$, while the other concentrations were significantly higher than that of the control, and reached the maximum value when the concentration reached $180 \mathrm{mmol} \cdot \mathrm{L}^{-1}$, which was 2.75 times higher than that of the control. In the $\mathrm{C}$ treatment group, the soluble sugar content in the set concentration was significantly higher than that in the control group, and reached the maximum value when the concentration reached $180 \mathrm{mmol} \cdot \mathrm{L}^{-1}$, an increase of 1.85 times compared with 
the control group. Soluble sugar content in B and E in the context of two groups of treatment group were in the concentration of $30 \mathrm{mmol} \cdot \mathrm{L}^{-1}$ reaches the minimum value, fell $39.1 \%$ and $41.1 \%$ than control, respectively, which may be caused by plant metabolism and synthesis, the two groups of the soluble sugar content increased with the increase of concentration of accumulating, until the concentration reaches 180 $\mathrm{mmol} \cdot \mathrm{L}^{-1}$, its content is also maximum, significant differences compared with than control, respectively 2.23 times and 2.42 times of the control; in the D treatment group, the soluble sugar content fluctuated greatly, showing an M-type growth pattern in the intermittent accumulation, and reached the peak value at $30 \mathrm{mmol} \cdot \mathrm{L}^{-1}$ and $90 \mathrm{mmol} \cdot \mathrm{L}^{-1}$, respectively, increasing by $140.5 \%$ and $196.9 \%$ compared with the control group. The soluble sugar content was significantly different from the control group when the concentration was $120 \mathrm{mmol} \cdot \mathrm{L}^{-1}$, but there was no significant change in other groups.

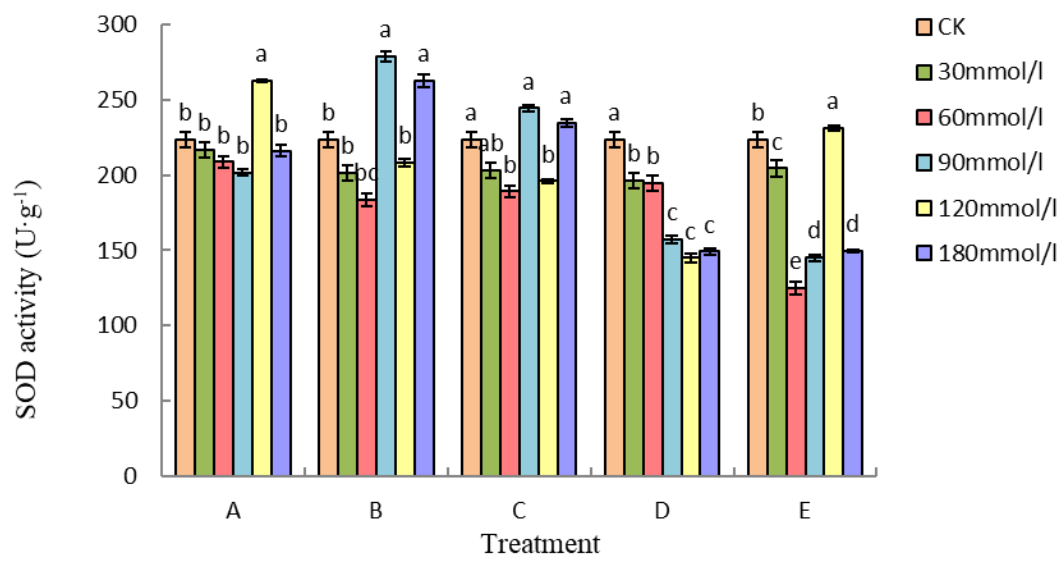

Figure 5. Changes in SOD activity in P. giganteum seedlings under saline-alkali stress

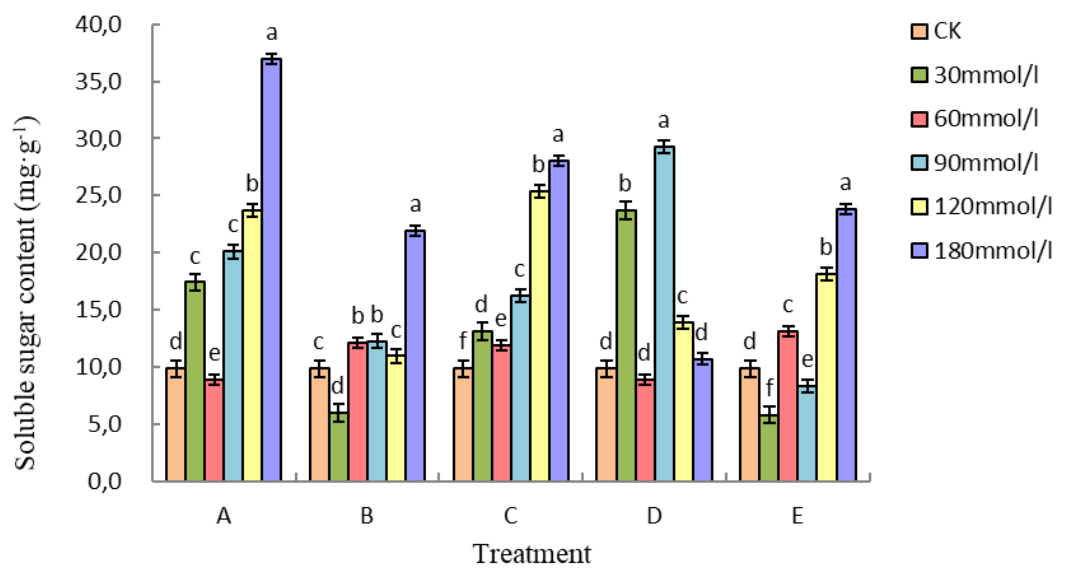

Figure 6. Changes in soluble sugar content in P. giganteum seedlings under saline-alkali stress

It can be seen from Figure 7 that the free proline in the 5 treatment groups will show a trend of different amplitude change, but the overall increase is with the increase of salt concentration. In treatment group A, D and E, the overall trend first increased to the peak value and then decreased slightly. In treatment group $\mathrm{A}$ and $\mathrm{E}$, the peak value appeared at the concentration of $120 \mathrm{mmol} \cdot \mathrm{L}^{-1}$, increased by 45.78 times and 44.70 
times compared with the control, while in treatment group D, the peak value appeared at the concentration of $120 \mathrm{mmol} \cdot \mathrm{L}^{-1}$, increased by 38.76 times compared with the control; in treatment group $\mathrm{B}$ and $\mathrm{C}$, free proline content showed M-type growth At the same time, it reached the peak at the concentration of $90 \mathrm{mmol} \cdot \mathrm{L}^{-1}$ and $180 \mathrm{mmol} \cdot \mathrm{L}^{-1}$, and reached the maximum at the concentration of $180 \mathrm{mmol} \cdot \mathrm{L}^{-1}$, which were 33.30 times and 51.92 times higher than the control.

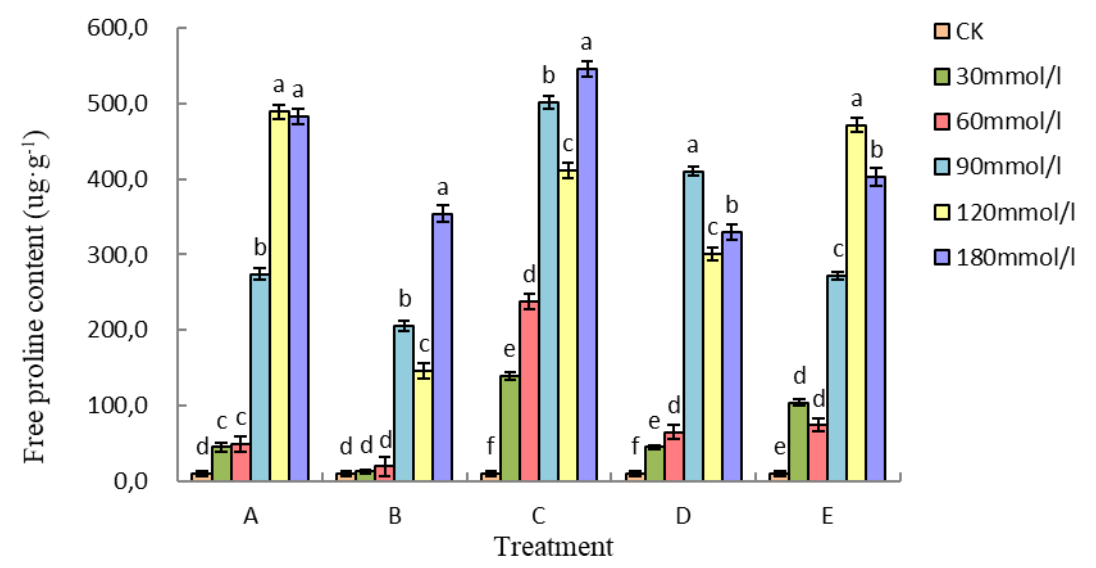

Figure 7. Changes in free proline content in P. giganteum seedlings under saline-alkali stress

Figure 8 shows that the soluble protein in the environment of increased concentration of each stress group shows the rule of gradual increase. Similarly, the soluble protein in the $\mathrm{A}$ and $\mathrm{D}$ stress group showed the rule of decreasing after increasing. In the treatment group, when the concentration of the stress environment was $60 \mathrm{mmol} \cdot \mathrm{L}^{-1}, 90 \mathrm{mmol} \cdot \mathrm{L}^{-1}$ and $120 \mathrm{mmol} \cdot \mathrm{L}^{-1}$, the content was significantly higher than that of the control group, and the peak value appeared at the concentration of 90 $\mathrm{mmol} \cdot \mathrm{L}^{-1}$. However, there was no significant difference in soluble protein content between the two groups. In the stress group $\mathrm{D}$, except that the soluble protein content of $30 \mathrm{mmol} \cdot \mathrm{L}^{-1}$ was slightly lower than that of the control and there was no significant difference, the soluble protein content of other concentrations under stress appeared significant, and the peak value appeared at $120 \mathrm{mmol} \cdot \mathrm{L}^{-1}$, increased by $8.9 \%$ compared with the control. For the treatment group B with low proportion of basic salt and the treatment group $\mathrm{E}$ with high proportion of basic salt, when the mixed salt concentration is lower $\left(<90 \mathrm{mmol} \cdot \mathrm{L}^{-1}\right)$, the soluble protein almost does not increase or the increase amount is very small, or even decreases. When the environmental concentration reaches $\leq 120 \mathrm{mmol} \cdot \mathrm{L}^{-1}$, the soluble protein content in the treatment group E increases all the time, and there is significant difference until it reaches the peak value, compared with the control group, the concentration of soluble protein in treatment B increased by $8.94 \%$. When the concentration of stress increased to $180 \mathrm{mmol} \cdot \mathrm{L}^{-1}$, soluble protein content in treatment B reached the peak value, which was 1.05 times higher than that in the control group. In the $\mathrm{C}$ treatment group, under the increasing stress environment, the soluble protein will change in the form of W-type. When the mixed salt concentration is $30 \mathrm{mmol} \cdot \mathrm{L}^{-1}$ and $120 \mathrm{mmol} \cdot \mathrm{L}^{-1}$, it reaches the minimum value of $\mathrm{W}$-type accumulation mode. Although the content is reduced, it does not show significant. When the concentration was $90 \mathrm{mmol} \cdot \mathrm{L}^{-1}$ and $120 \mathrm{mmol} \cdot \mathrm{L}^{-1}$, the peak value of this accumulation was 1.05 and 1.07 times of the control. 


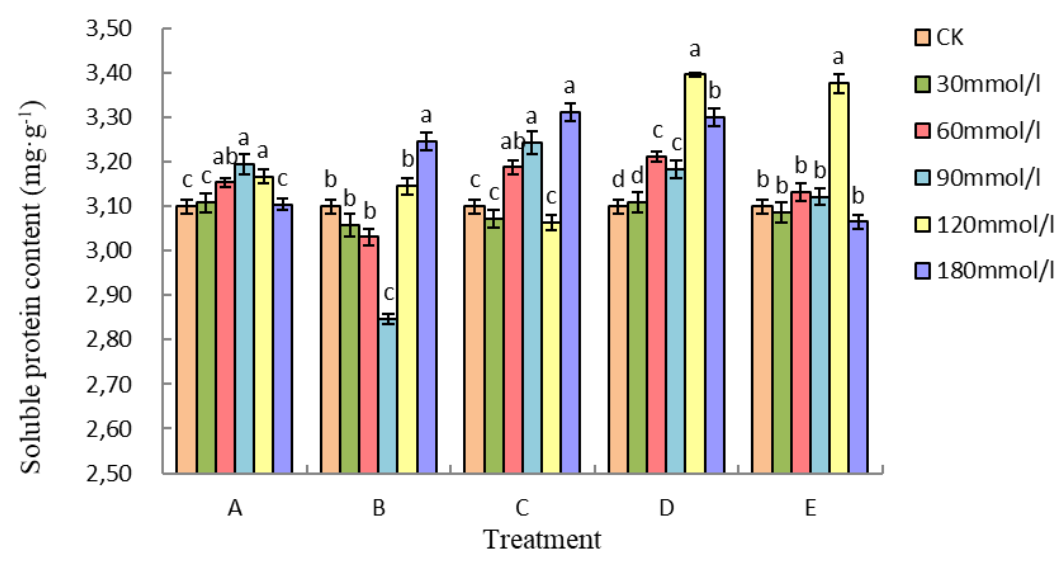

Figure 8. Changes in soluble protein content in P. giganteum seedlings under saline-alkali stress

\section{Effects of mixed saline-alkali stress on $\mathrm{Na}^{+}$content in various organs}

$\mathrm{The} \mathrm{Na}^{+}$content in the roots of each treatment group accumulated continuously with the increase of salt solution concentration, but the process of accumulation did not continue to increase (Fig. 9). In treatment group A, B, C and E, with the increase of mixed salt concentration, the $\mathrm{Na}^{+}$content in the root of $P$. giganteum increased at first, then decreased and then increased, and reached the maximum when the salt concentration was $180 \mathrm{mmol} \cdot \mathrm{L}^{-1}$, which was significantly different from that of the control, which was 7.06, 7.40, 4.31, 7.96 times higher than that of the control, respectively. In group A, when the concentration was in the range of $30-90 \mathrm{mmol} \cdot \mathrm{L}^{-1}$, the accumulation rate of the $\mathrm{Na}^{+}$in the root of $P$. giganteum became very slow or even decreased after reaching a certain amount, and when the concentration continued to increase, the content began to increase abruptly until it reached the maximum value. In group $\mathrm{B}$ and $\mathrm{C}$, the $\mathrm{Na}^{+}$content decreased significantly when the concentration was in the range of 0-90 $\mathrm{mmol} \cdot \mathrm{L}^{-1}$. In the D treatment group, when the solution concentration was $30 \mathrm{mmol} \cdot \mathrm{L}^{-1}$ and $60 \mathrm{mmol} \cdot \mathrm{L}^{-1}$, the $\mathrm{Na}^{+}$content continued to increase, and there was a significant difference between the control. With the increase of the concentration, the $\mathrm{Na}^{+}$content began to decrease significantly, and the $\mathrm{Na}^{+}$content began to increase at the concentration of $120 \mathrm{mmol} \cdot \mathrm{L}^{-1}$, until it reached the maximum at $180 \mathrm{mmol} \cdot \mathrm{L}^{-1}$.

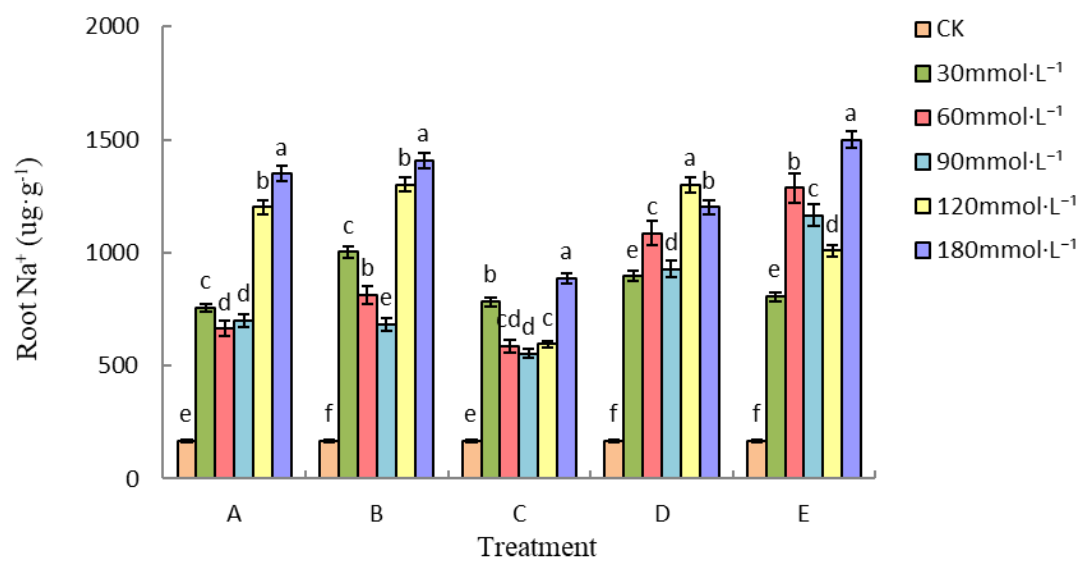

Figure 9. Change of the $\mathrm{Na}^{+}$content in root of $\mathrm{P}$. giganteum seedlings under saline-alkali stress 
In the A treatment group with pure salt ratio, the $\mathrm{Na}^{+}$content increased significantly with the increase of concentration, until the concentration changed to $180 \mathrm{mmol} \cdot \mathrm{L}^{-1}$, the $\mathrm{Na}^{+}$content reached the maximum, which was 36.99 times higher than that of the control. In group $\mathrm{B}, \mathrm{C}$ and $\mathrm{D}$, the $\mathrm{Na}^{+}$content increased continuously with the increase of salt solution concentration and reached the maximum when the concentration was $180 \mathrm{mmol} \cdot \mathrm{L}^{-1}$ which was 33.6 times, 32.0 times and 42.9 times higher than that of the control, respectively. In the E treatment group, the $\mathrm{Na}^{+}$content in the stem increased at first, then decreased and then increased with the increase of concentration, and finally reached the maximum when the concentration was $180 \mathrm{mmol} \cdot \mathrm{L}^{-1}$, which was 43.6 times higher than that of the control. On the whole, the accumulation of the $\mathrm{Na}^{+}$content in the stem of treatment group A, D and E was more than that of treatment group B and C, and the $\mathrm{Na}^{+}$content of treatment group $\mathrm{E}$ reached the maximum in the whole stress (Fig. 10).

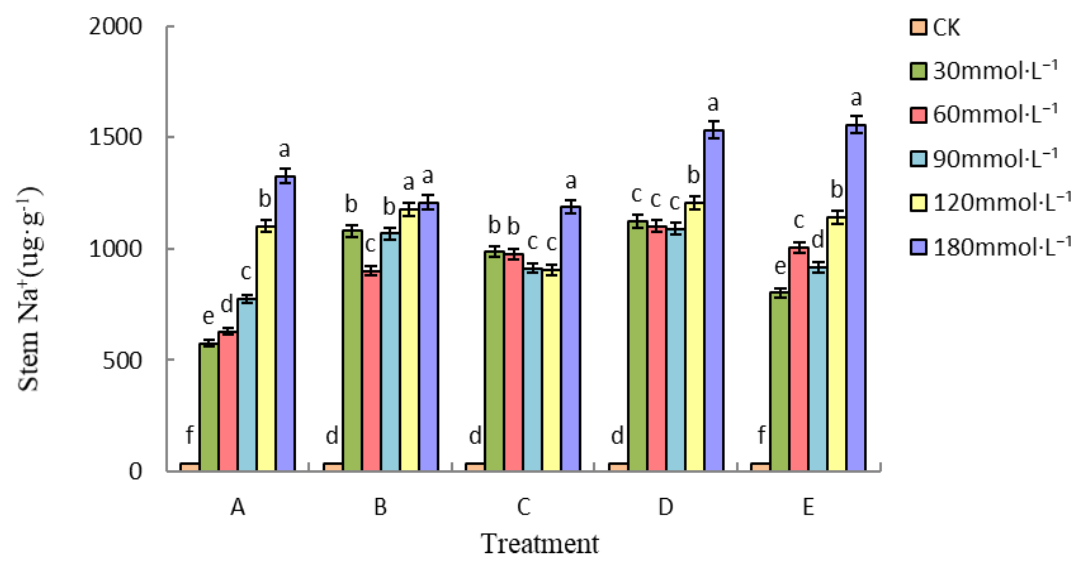

Figure 10. Change of the $\mathrm{Na}^{+}$content in stem of $\mathrm{P}$. giganteum seedlings under saline-alkali stress

In group $\mathrm{A}, \mathrm{B}$ and $\mathrm{E}$, the $\mathrm{Na}^{+}$content in leaves reached the maximum when the concentration was $180 \mathrm{mmol} \cdot \mathrm{L}^{-1}$, which was $21.62,26.09,25.11$ times as much as that of the control, respectively. Treatment A showed a linear and significant increasing trend until the maximum value, and treatment $\mathrm{B}$ showed a law of accumulation that increased at first and then decreased and then increased. In group $\mathrm{C}$, the $\mathrm{Na}^{+}$content in leaves increased at first and then decreased, and reached the peak at the concentration of $90 \mathrm{mmol} \cdot \mathrm{L}^{-1}$, which was 18.35 times higher than that of the control, while in group $\mathrm{D}$, the $\mathrm{Na}^{+}$content in leaves showed an M-type increasing trend, that is, increasingdecreasing-increasing-decreasing. The peak appeared when the concentration of the solution was $60 \mathrm{mmol} \cdot \mathrm{L}^{-1}$ and $120 \mathrm{mmol} \cdot \mathrm{L}^{-1}$, and reached the maximum when the concentration was $120 \mathrm{mmol} \cdot \mathrm{L}^{-1}$, which was 20.64 times higher than that of the control (Fig. 11).

\section{Effects of mixed saline-alkali stress on $\mathrm{K}^{+}$content in various organs}

For the root of $P$. giganteum, the $\mathrm{K}^{+}$content in groups $\mathrm{A}$ and $\mathrm{B}$ with low ratio of pure salt and alkaline salt was significantly lower than that of the control group, and the $\mathrm{K}^{+}$ content in group A changed little when the solution concentration was $\geq 30 \mathrm{mmol} \cdot \mathrm{L}^{-1}$, and the $\mathrm{K}^{+}$content remained at a stable level. In group $\mathrm{B}$ and $\mathrm{C}$, the $\mathrm{K}^{+}$content showed a "W" pattern with the increase of concentration, that is, the trend of "decrease-increase- 
decrease-increase". When the concentration was $90 \mathrm{mmol} \cdot \mathrm{L}^{-1}$, the $\mathrm{K}^{+}$content in group $\mathrm{C}$ reached the maximum value of the whole treatment group, which was 1.04 times higher than that of the control, but it was not significant. In the D and E groups with relatively large alkaline salt, the root $\mathrm{K}^{+}$content increased and reached the maximum at the concentration of $30 \mathrm{mmol} \cdot \mathrm{L}^{-1}$, which increased by $24.5 \%$ (significantly higher than the control) and 3.20\% (no significant increase compared with the control), respectively, while the root $\mathrm{K}^{+}$content of the two groups was significantly lower than that of the control at other concentrations and reached the minimum at the concentrations of 180 $\mathrm{mmol} \cdot \mathrm{L}^{-1}$ and $120 \mathrm{mmol} \cdot \mathrm{L}^{-1}$, respectively (Fig. 12). Compared with the control, it decreased by $70.2 \%$ and $68.0 \%$.

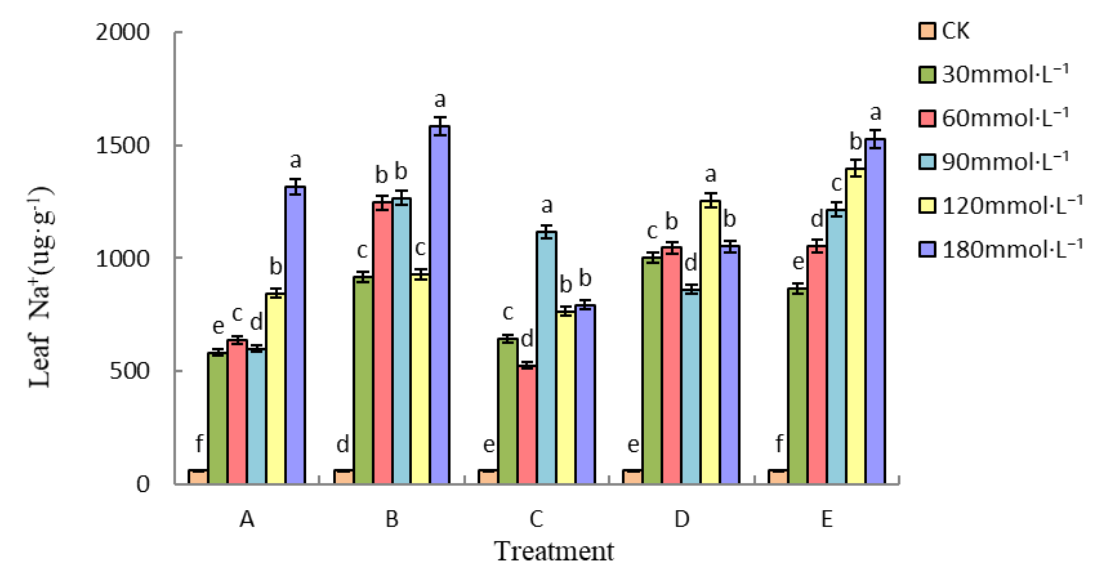

Figure 11. Change of the $\mathrm{Na}^{+}$content in leaf of $\mathrm{P}$. giganteum seedlings under saline-alkali stress

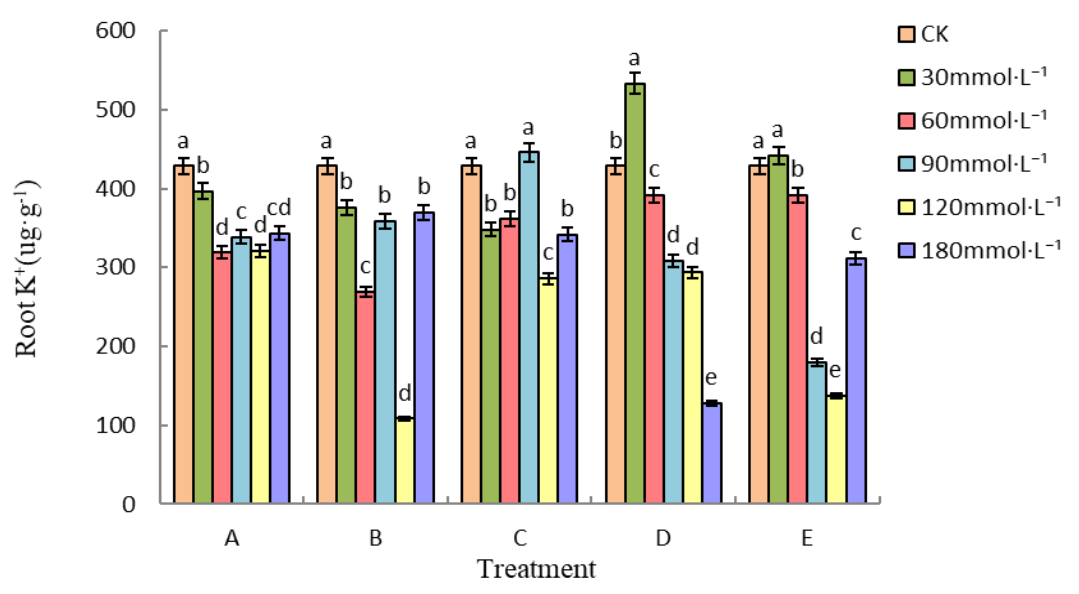

Figure 12. Change of the $K^{+}$content in root of $P$. giganteum seedlings under saline-alkali stress

For stems, the $\mathrm{K}^{+}$content decreased significantly with the increase of mixed salt concentration in A, B, C and D groups, but the decreasing trend was different (Fig. 13). Among them, in the $\mathrm{A}$ and $\mathrm{C}$ treatment groups, the $\mathrm{K}^{+}$content decreased at first and then increased with the increase of the solution concentration, and the two groups reached the lowest value at the concentration of $90 \mathrm{mmol} \cdot \mathrm{L}^{-1}$ at the same time, which decreased by $34.2 \%$ and $33.7 \%$, respectively compared with the control. In group B, the 
$\mathrm{K}^{+}$content fluctuated and decreased with the increase of concentration. In the $\mathrm{D}$ treatment group, the $\mathrm{K}^{+}$content decreased significantly with the increase of the mixed salt concentration, and when the concentration was $180 \mathrm{mmol} \cdot \mathrm{L}^{-1}$, the $\mathrm{K}^{+}$content of the stem decreased to the lowest value of the whole treatment group, which decreased by $89.2 \%$ compared with the control. In the E treatment group with high alkaline salt ratio, the $\mathrm{K}^{+}$content increased significantly with the increase of mixed salt concentration, and reached the maximum when the concentration was $180 \mathrm{mmol} \cdot \mathrm{L}^{-1}$, which was 1.58 times higher than that of the control.

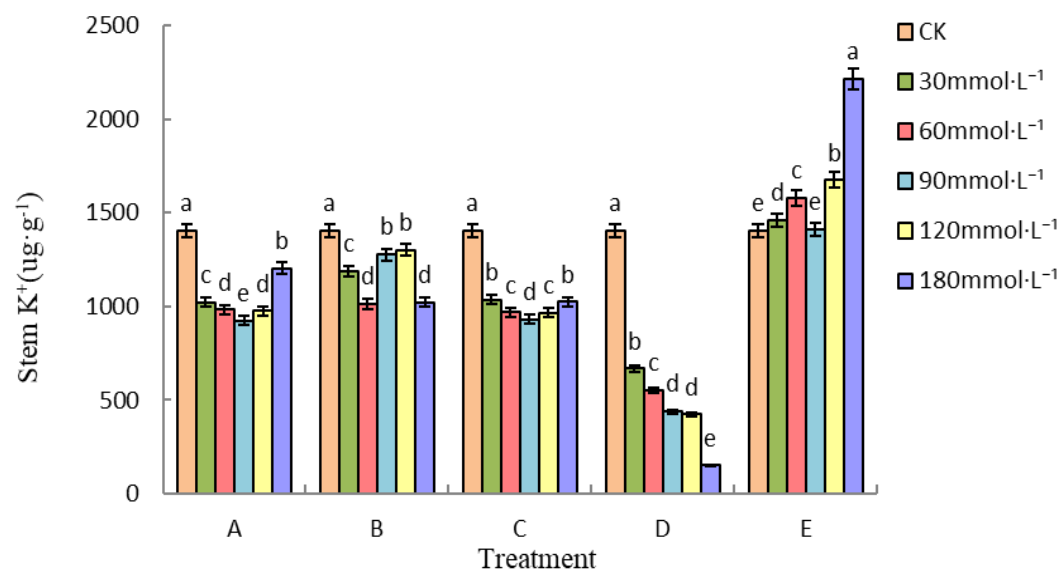

Figure 13. Change of the $K^{+}$content in stem of $P$. giganteum seedlings under saline-alkali stress

For leaves, in different treatment groups, the $\mathrm{K}^{+}$content increased significantly with the increase of the concentration of mixed salt solution. In A, B, C and D treatment groups, the $\mathrm{K}^{+}$content showed the law of fluctuation and accumulation, while the $\mathrm{K}^{+}$ content in $\mathrm{E}$ treatment group increased linearly. In the A treatment group with pure salt ratio and the $\mathrm{E}$ treatment group with high alkaline salt ratio, the $\mathrm{K}^{+}$content in leaves reached the maximum when the concentration of mixed salt was $180 \mathrm{mmol} \cdot \mathrm{L}^{-1}$, which was 4.51 times and 5.33 times higher than that of the control, respectively. In groups B, $\mathrm{C}$ and $\mathrm{D}$ with low alkaline salt, the $\mathrm{K}^{+}$content in leaves reached the maximum when the concentration of mixed salt was $30 \mathrm{mmol} \cdot \mathrm{L}^{-1}$, which was $3.12,2.39$ and 3.36 times higher than that of the control, respectively (Fig. 14). From the point of view of each treatment group, the $\mathrm{K}^{+}$content in leaves of $\mathrm{E}$ treatment group with high alkaline salt ratio was significantly higher than that of other concentrations, thus it can be seen that under high alkali environment, it will promote the accumulation of the $\mathrm{K}^{+}$content in $P$. giganteum leaves to balance the normal metabolic function of plants.

\section{Effects of mixed saline-alkali stress on the ratio of the $\mathrm{Na}^{+}$to $\mathrm{K}^{+}$in different organs}

As can be seen from Figure 15 , the $\mathrm{K}^{+} / \mathrm{Na}^{+}$ratio of the roots, stems and leaves of $P$. giganteum seedlings in the treatment groups with different ratios had a small change range and was significantly lower than that of the control groups. In the three treatment groups of $\mathrm{A}, \mathrm{C}$ and $\mathrm{D}$, the $\mathrm{K}^{+} / \mathrm{Na}^{+}$ratio at the root decreased to the minimum when the concentration of mixed salt was $180 \mathrm{mmol} \cdot \mathrm{L}^{-1}$, which decreased by $90.08 \%, 84.97 \%$ and $95.86 \%$, respectively. In the two treatment groups of $\mathrm{B}$ and $\mathrm{E}$, the ratio of the $\mathrm{K}^{+} / \mathrm{Na}^{+}$at the root decreased to the minimum when the concentration of mixed salt was 
$120 \mathrm{mmol} \cdot \mathrm{L}^{-1}$, which decreased by $96.76 \%$ and $94.69 \%$, respectively compared with the control group. In each treatment group, the ratio of the $\mathrm{K}^{+} / \mathrm{Na}^{+}$of stem in different mixed salt concentrations decreased little, with no significant difference, and the decrease was greater than $95 \%$. In the $\mathrm{D}$ treatment group with a concentration of 180 $\mathrm{mmol} \cdot \mathrm{L}^{-1}$, the ratio of the $\mathrm{K}^{+} / \mathrm{Na}^{+}$of stem decreased the most, which was $99.13 \%$ lower than that of the control group. For the leaves, the decrease of the $\mathrm{K}^{+} / \mathrm{Na}^{+}$ratio in the two treatment groups $\mathrm{A}$ and $\mathrm{E}$ at different mixed salt concentrations was not significant. The $\mathrm{K}^{+} / \mathrm{Na}^{+}$ratio of $\mathrm{B}, \mathrm{C}$ and $\mathrm{D}$ treatment group decreased significantly compared with the control group, and the decrease was significantly different under various mixed salt concentrations. Among them, the ratio of the $\mathrm{K}^{+} / \mathrm{Na}^{+}$in the middle lobe of the $\mathrm{B}$ and $\mathrm{D}$ treatment groups was reduced to the minimum when it was $180 \mathrm{mmol} \cdot \mathrm{L}^{-1}$, which decreased by $90.87 \%$ and $87.34 \%$ respectively compared with the control group. However, the ratio of the $\mathrm{K}^{+} / \mathrm{Na}^{+}$in the middle lobe of the $\mathrm{C}$ treatment group was reduced to the minimum at $90 \mathrm{mmol} \cdot \mathrm{L}^{-1}$, which was $84.55 \%$ lower than that of the control group.

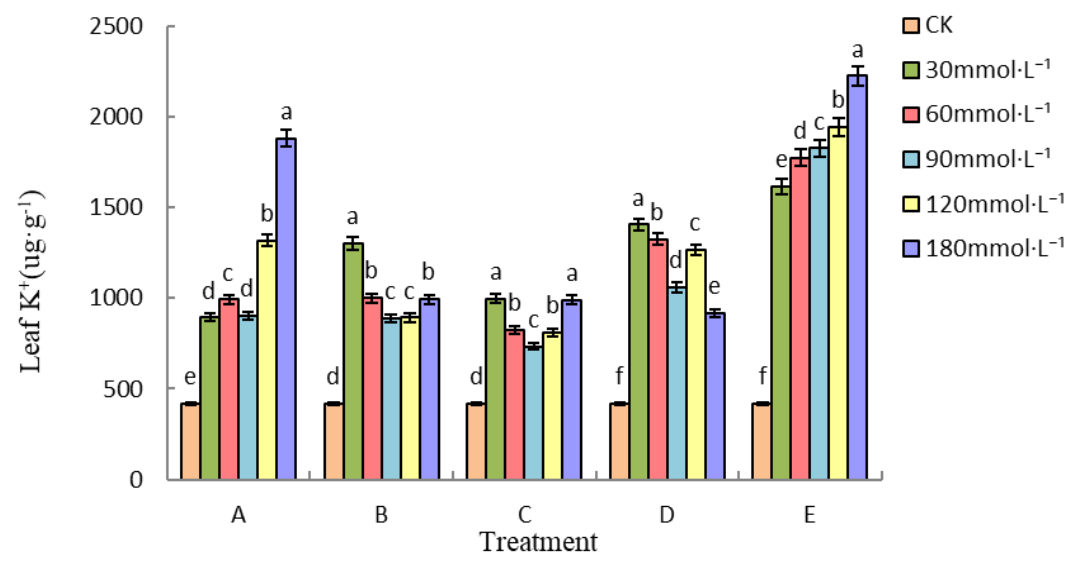

Figure 14. Change of the $K^{+}$content in leaf of $P$. giganteum seedlings under saline-alkali stress

\section{Effects of mixed saline-alkali stress on selective transport capacity of mineral ions in individual organs}

Table 2 shows that there is a positive correlation between the selective transport of the $\mathrm{K}^{+}$and the selective coefficient of $\mathrm{S}_{\mathrm{K}, \mathrm{Na}}$ under mixed saline-alkali stress, that is, the higher the selective coefficient of $S_{\mathrm{K}, \mathrm{Na}}$, the stronger the selective transport of the $\mathrm{K}^{+}$by plants. In different treatment groups, with the increase of the concentration of salinealkali mixed solution, the value of $S_{K, N a}$ transported from root to stem showed a downward trend, and the value of $S_{K, N a}$ was lower or significantly lower than that of the control, while in the same treatment group, with the increase of the concentration of saline-alkali mixed solution, the value of $S_{K, N a}$ transported from stem to leaf increased, and the value of $S_{\mathrm{K}, \mathrm{Na}}$ was significantly higher than that of the control. Thus it can be seen that in the process of mixed stress, the selective transport of stem inhibited the transport process of the $\mathrm{Na}^{+}$in varying degrees, hindered its entry into the leaves, and enhanced the transport capacity of the $\mathrm{K}^{+}$to a certain extent, making more $\mathrm{K}^{+}$into the leaves. On the other hand, the selective transport in the root is opposite to that in the stem, that is, it enhances the transport capacity of the $\mathrm{Na}^{+}$, but inhibits the transport process of the $\mathrm{K}^{+}$in varying degrees and weakens its absorption. However, in different 
ratios of $\mathrm{A}, \mathrm{B}, \mathrm{C}$ and $\mathrm{E}$ treatment groups, the $\mathrm{S}_{\mathrm{K}, \mathrm{Na}}$ value transported from root to stem under various concentration stress was higher than that from stem to leaf at the corresponding concentration, while in D treatment group with higher alkaline salt ratio, the change rule of $S_{K, N a}$ value was the opposite. The results showed that the ability of transporting $\mathrm{K}^{+}$from stem to leaf was stronger than that of stem to leaf in $\mathrm{A}, \mathrm{B}, \mathrm{C}$ and $\mathrm{E}$ treatment groups, and wanted to intercept more $\mathrm{Na}^{+}$, and keep it in the root to reduce the damage of saline-alkali mixed stress to aboveground parts, while in D treatment group, the ability of stem to transport $\mathrm{K}^{+}$to leaf was stronger than that of root to stem, which balanced and ensured the normal physiological metabolism of leaves to some extent.
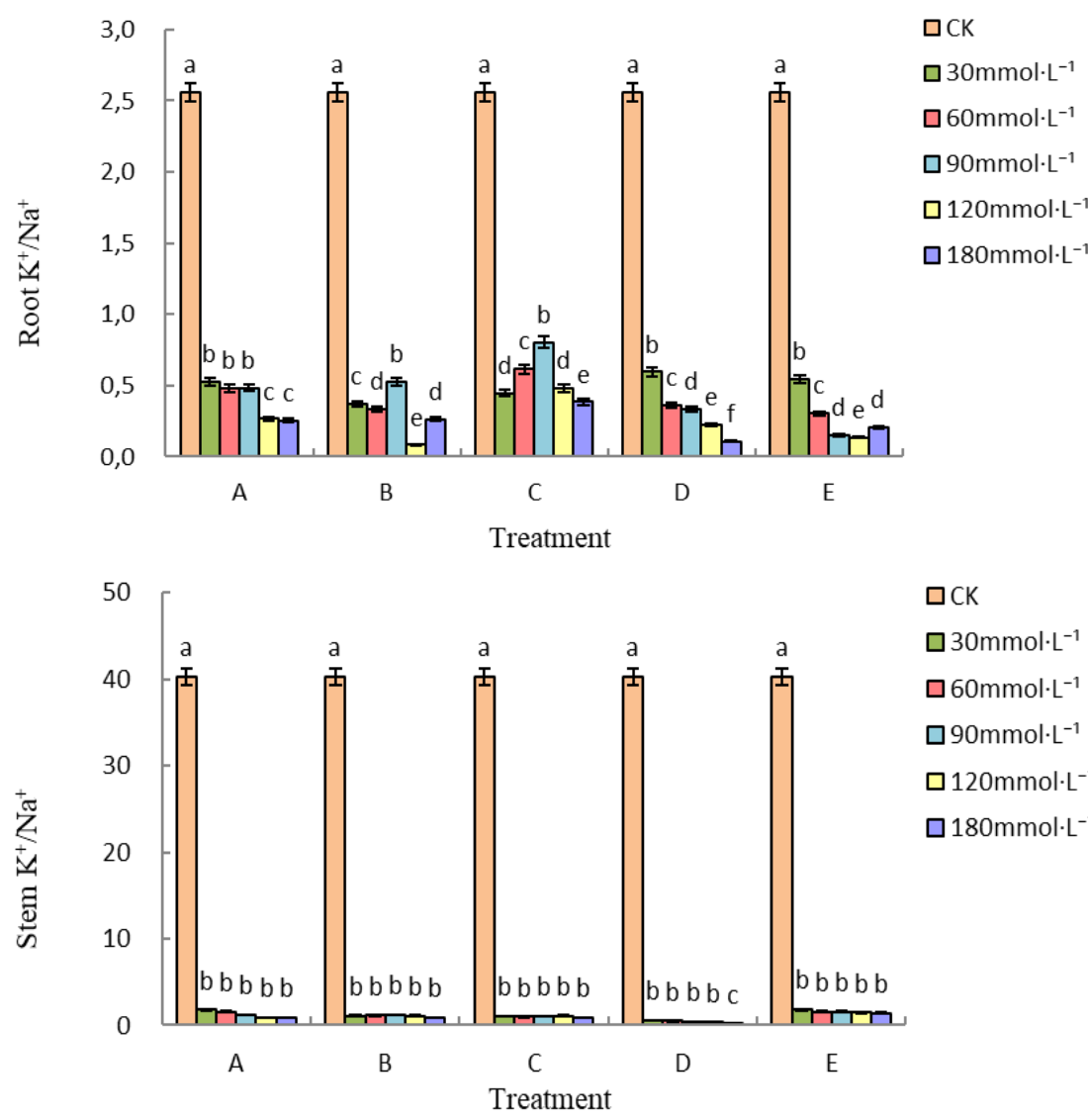

$\square$ CK

$\square 30 \mathrm{mmol} \cdot \mathrm{L}^{-1}$

$\square 60 \mathrm{mmol} \cdot \mathrm{L}^{-1}$

$\square 90 \mathrm{mmol} \cdot \mathrm{L}^{-1}$

$\square 120 \mathrm{mmol} \cdot \mathrm{L}^{-1}$

$\square 180 \mathrm{mmol} \cdot \mathrm{L}^{-1}$

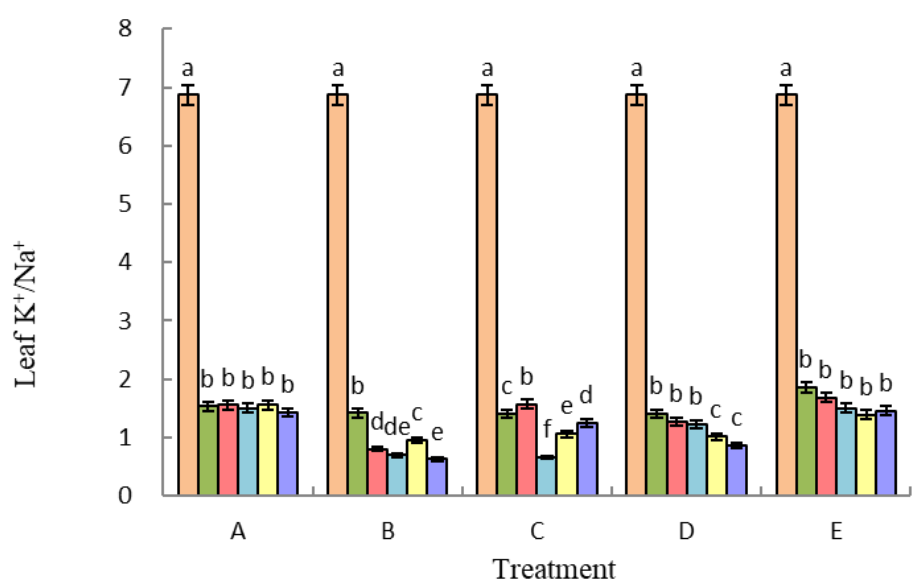

$\square \mathrm{CK}$

$\square 30 \mathrm{mmol} \cdot \mathrm{L}^{-1}$

$\square 60 \mathrm{mmol} \cdot \mathrm{L}^{-1}$

口90 $\mathrm{mmol} \cdot \mathrm{L}^{-1}$

$\square 120 \mathrm{mmol} \cdot \mathrm{L}^{-1}$

$\square 180 \mathrm{mmol} \cdot \mathrm{L}^{-1}$

Figure 15. Change of the $\mathrm{K}^{+} / \mathrm{Na}^{+}$ratios in different organs of $P$. giganteum seedlings under saline-alkali stress 
Table 2. Effect of saline-alkali stress on transporting selective ratios of the $\mathrm{K}^{+}$to $\mathrm{Na}^{+}$in $P$. giganteum

\begin{tabular}{|c|c|c|c|}
\hline \multirow{2}{*}{\multicolumn{2}{|c|}{$\begin{array}{l}\text { Saline-alkali mixture ratio and } \\
\text { concentration }\left(\mathrm{mmol}^{\circ} \mathrm{L}^{-1}\right)\end{array}$}} & \multicolumn{2}{|c|}{$\mathbf{S}_{\mathbf{K}, \mathbf{N a}}$} \\
\hline & & Root - stem & Stem-leaf \\
\hline \multirow{6}{*}{ A } & CK & $15.72 \pm 0.63 \mathrm{a}$ & $0.17 \pm 0.01 \mathrm{e}$ \\
\hline & 30 & $3.39 \pm 0.02 b$ & $0.86 \pm 0.02 \mathrm{~d}$ \\
\hline & 60 & $3.26 \pm 0.04 b c$ & $0.99 \pm 0.02 \mathrm{c}$ \\
\hline & 90 & $2.46 \pm 0.04 \mathrm{c}$ & $1.26 \pm 0.03 b$ \\
\hline & 120 & $3.31 \pm 0.00 \mathrm{bc}$ & $1.76 \pm 0.01 \mathrm{a}$ \\
\hline & 180 & $3.57 \pm 0.02 \mathrm{~b}$ & $1.58 \pm 0.02 \mathrm{a}$ \\
\hline \multirow{6}{*}{ B } & CK & $15.72 \pm 0.63 \mathrm{a}$ & $0.17 \pm 0.01 \mathrm{e}$ \\
\hline & 30 & $2.93 \pm 0.03 b$ & $1.29 \pm 0.02 \mathrm{a}$ \\
\hline & 60 & $3.38 \pm 0.19 b$ & $0.71 \pm 0.02 \mathrm{c}$ \\
\hline & 90 & $2.28 \pm 0.06 \mathrm{~b}$ & $0.59 \pm 0.01 \mathrm{~d}$ \\
\hline & 120 & $13.28 \pm 1.36 \mathrm{a}$ & $0.87 \pm 0.00 \mathrm{~b}$ \\
\hline & 180 & $3.22 \pm 0.11 \mathrm{~b}$ & $0.74 \pm 0.01 \mathrm{c}$ \\
\hline \multirow{6}{*}{$\mathrm{C}$} & CK & $15.72 \pm 0.63 \mathrm{a}$ & $0.17 \pm 0.01 \mathrm{e}$ \\
\hline & 30 & $2.36 \pm 0.01 b$ & $1.33 \pm 0.02 b$ \\
\hline & 60 & $1.61 \pm 0.04 \mathrm{~cd}$ & $1.58 \pm 0.01 \mathrm{a}$ \\
\hline & 90 & $1.27 \pm 0.01 \mathrm{~d}$ & $0.64 \pm 0.02 \mathrm{~d}$ \\
\hline & 120 & $2.22 \pm 0.02 b c$ & $0.99 \pm 0.01 \mathrm{c}$ \\
\hline & 180 & $2.24 \pm 0.01 \mathrm{~b}$ & $1.45 \pm 0.03 \mathrm{~b}$ \\
\hline \multirow{6}{*}{$\mathrm{D}$} & CK & $15.72 \pm 0.63 \mathrm{a}$ & $0.17 \pm 0.01 \mathrm{~d}$ \\
\hline & 30 & $0.99 \pm 0.04 b$ & $2.36 \pm 0.05 \mathrm{c}$ \\
\hline & 60 & $1.39 \pm 0.02 b$ & $2.52 \pm 0.12 \mathrm{c}$ \\
\hline & 90 & $1.21 \pm 0.02 \mathrm{~b}$ & $3.05 \pm 0.31 \mathrm{~b}$ \\
\hline & 120 & $1.56 \pm 0.05 b$ & $2.86 \pm 0.42 b$ \\
\hline & 180 & $0.93 \pm 0.00 \mathrm{~b}$ & $8.79 \pm 0.41 \mathrm{a}$ \\
\hline \multirow{6}{*}{$\mathrm{E}$} & $\mathrm{CK}$ & $15.72 \pm 0.63 \mathrm{a}$ & $0.17 \pm 0.01 \mathrm{c}$ \\
\hline & 30 & $3.31 \pm 0.02 \mathrm{f}$ & $1.03 \pm 0.02 \mathrm{ab}$ \\
\hline & 60 & $5.16 \pm 0.01 \mathrm{e}$ & $1.07 \pm 0.02 \mathrm{a}$ \\
\hline & 90 & $10.00 \pm 0.34 \mathrm{c}$ & $1.02 \pm 0.01 \mathrm{ab}$ \\
\hline & 120 & $12.76 \pm 0.33 b$ & $0.95 \pm 0.04 b$ \\
\hline & 180 & $6.86 \pm 0.28 \mathrm{~d}$ & $1.02 \pm 0.01 \mathrm{ab}$ \\
\hline
\end{tabular}

Different treatments: A) $\mathrm{NaCl}: \mathrm{Na}_{2} \mathrm{SO}_{4}: \mathrm{NaHCO}_{3}: \mathrm{Na}_{2} \mathrm{CO}_{3}=1: 1: 0: 0$, B) $\mathrm{NaCl}: \mathrm{Na}_{2} \mathrm{SO}_{4}: \mathrm{NaHCO}_{3}$ : $\mathrm{Na}_{2} \mathrm{CO}_{3}=1: 2: 1: 0$, C) $\mathrm{NaCl}: \mathrm{Na}_{2} \mathrm{SO}_{4}: \mathrm{NaHCO}_{3}: \mathrm{Na}_{2} \mathrm{CO}_{3}=1: 9: 9: 1$, D) $\mathrm{NaCl}: \mathrm{Na}_{2} \mathrm{SO}_{4}: \mathrm{NaHCO}_{3}:$ $\mathrm{Na}_{2} \mathrm{CO}_{3}=1: 1: 1: 1$, E) $\mathrm{NaCl}: \mathrm{Na}_{2} \mathrm{SO}_{4}: \mathrm{NaHCO}_{3}: \mathrm{Na}_{2} \mathrm{CO}_{3}=9: 1: 1: 9$. Different letters indicate significant difference $(\mathrm{P} \leq 0.05)$ among various concentrations in the same treatment based on least significant difference test (LSD)

\section{Discussion}

Saline-alkali stress is a particularly significant way to limit the normal growth and development of plants (Jia et al., 2020). When plants were subjected to saline-alkali stress, the growth of plants was inhibited in varying degrees with the increase of concentration (Zhao et al., 2017; Lou et al., 2018; Anam et al., 2019). Farooq et al. (2017) on chickpea (Cicer arietinum L.) and Rasouli and Kiani-Pouya (2015) on Rye (Secale cereale L.) showed that under saline-alkali stress, plants could not absorb enough water and mineral nutrients, resulting in a decrease in $P n$, while consuming more organic matter to deal with osmotic stress and ion toxicity caused by saline-alkali stress, the most intuitive manifestation is the decrease of biomass. Many studies have shown that mixed saline-alkali compound stress is not a simple superposition of salinealkali stress, but has a certain synergistic effect. Plants are not only subjected to osmotic injury and ion toxicity caused by salt stress, but also affected by high $\mathrm{pH}$ caused by alkali stress (Guo et al., 2017). The results showed that the growth of plant height of $P$. 
giganteum was inversely proportional to the concentration of mixed salt, that is, the growth of plant height decreased gradually with the increase of salt concentration. In group A of pure salt solution and group B with lower proportion of alkaline salt, the growth of plant height decreased slowly when the solution concentration was lower 30 $\mathrm{mmol} \cdot \mathrm{L}^{-1}$ and $60 \mathrm{mmol} \cdot \mathrm{L}^{-1}$. However, in the latter three treatments with a large proportion of alkaline salt, the plant height growth decreased sharply with the increase of salt concentration, even in the mixed salt solution of low concentration of 30 $\mathrm{mmol} \cdot \mathrm{L}^{-1}$, the plant height growth was significantly lower than that of the control. This shows that the growth of $P$. giganteum is affected not only by salt concentration, but also by the synergistic effect of high $\mathrm{pH}$. Similar effects of saline-alkali mixed stress have been found in sunflower (Helianthus annuus L.) and alfalfa (Shi and Sheng, 2005; Peng et al., 2008).

A large number of active oxygen free radicals (Reactive Oxygen Species, ROS) in plants are produced in the process of saline-alkali stress. In the first line of defense of plant antioxidant system, SOD first scavenges reactive oxygen free radicals, and then converts $\mathrm{O}_{2}{ }^{-}$into $\mathrm{H}_{2} \mathrm{O}_{2}$ and $\mathrm{O}_{2}$ to achieve the purpose of antioxidation (Shafqat et al., 2019). The results showed that no matter what proportion of neutral salt and alkaline salt were mixed, the MDA content of $P$. giganteum was proportional to the salt concentration, and the MDA content increased continuously with the increase of salt concentration. This shows that mixed saline-alkali stress will lead to the accumulation of MDA in $P$. giganteum, and the degree of cell membrane peroxidation will increase continuously, whether in high-salt or high-alkali soil environment, it will lead to leaf peroxidation, thus affecting plant growth. Superoxide dismutase (SOD) is an important antioxidant enzyme, which can prevent the damage of reactive oxygen species to the cell membrane system (Zhang et al., 2019). During the whole stress process, the change range of CAT activity was less than that of SOD activity, which indicated that the antioxidant effect of CAT was relatively less than that of SOD under mixed salt stress. This is consistent with the results of the study of Amor in Sea rocket (Cakile maritime) (Amor et al., 2006).

Osmotic regulation is an important physiological mechanism for plants to resist adversity. Plants can regulate cell osmotic balance by synthesizing osmotic substances (proline, soluble sugars, organic acids, etc.) to increase their saline-alkali tolerance, so as to alleviate the damage caused by combined saline-alkali stress to plants (CapulaRodríguez et al., 2016). Some studies have shown that the accumulation of proline is not only a signal of plant response to saline-alkali stress, but also a kind of defensive behavior. In this experiment, the proline content of $P$. giganteum increased slowly at low salt concentration, but accumulated at high salt concentration, which was similar to the results of Yang et al. (2007). It shows that proline is not the product of osmotic stress, but the product of stress degree. This may be that $P$. giganteum has a certain tolerance to saline-alkali compound stress, accumulate a large amount of proline when it exceeds the tolerance range, and alleviate the damage caused by saline-alkali compound stress, until it cannot bear the stress of high salt and high alkali. For soluble protein and soluble sugar, in the process of low concentration or slow increase, soluble protein and soluble sugar will increase periodically, when the concentration reaches a certain level, these two regulatory substances will also increase sharply to balance their own metabolism. It can be seen that $P$. giganteum can balance and regulate its own metabolism to a certain degree of stress, showing a certain ability to adapt. 
Saline-alkali stress will produce ion toxicity to plants. Plant roots will maintain ion homeostasis inside and outside the cell or tissue by regulating the entry and exit of intracellular ions. Under compound saline-alkali stress, maintaining high $\mathrm{K}^{+} / \mathrm{Na}^{+}$ratio in leaves is an important index of plant saline-alkali tolerance (Shaheen et al., 2016). Ma et al. (2011) analyzed the ion contents of the $\mathrm{K}^{+}, \mathrm{Na}^{+}$and $\mathrm{Ca}^{2+}$ in roots, underground stems and aboveground parts of Chinese leymus (Leymus chinensis) treated for 6 months under different degrees of alkali stress, and revealed the mechanism of Leymus chinensis maintaining ion balance under saline-alkali stress. The results showed that the $\mathrm{Na}^{+}$content in roots was lower, but the selective absorption of the $\mathrm{K}^{+}$and $\mathrm{Ca}^{2+}$ was stronger, which ensured a higher ratio of the $\mathrm{K}^{+} / \mathrm{Na}^{+}$and $\mathrm{Ca}^{2+} / \mathrm{Na}^{+}$. It is an important mechanism for Leymus chinensis to adapt to alkali stress. $\mathrm{Na}^{+}$is one of the necessary elements for the growth and development of plants in saline-alkali soil, and its content can directly affect the salt tolerance of plants. The results of this experiment show that the accumulation of the $\mathrm{Na}^{+}$in the upper part (stem and leaf) is larger than that in the underground part (root), which indicates that there is a strict regulation mechanism for the absorption and transport of the $\mathrm{Na}^{+}$, and the regional distribution of the $\mathrm{Na}^{+}$, this mechanism well avoids the excessive accumulation of ions in a certain organ of the plant, thus avoiding ion toxicity (Liu et al., 2015). As a necessary element for plant growth and a key ion for osmotic regulation, $\mathrm{K}^{+}$participates in the activation of more than 50 enzymes needed for chlorophyll synthesis (Azarin et al., 2016). When the plant growth is not stressed, the cells contain more $\mathrm{K}^{+}$, so as to maintain the normal growth of the plant. In this study, the $\mathrm{K}^{+}$content in different organs decreased with the increase of salt solution concentration, which was opposite to that of the $\mathrm{Na}^{+}$. This shows that there is a certain competition between $\mathrm{Na}^{+}$and $\mathrm{K}^{+}$, which is also a cation to maintain the normal function of cells, which is caused by the antagonism of ions, because they have similar physical and chemical properties, that is, the radius of ions is similar to the hydration energy of ions. At the same time, in this study, the ratio of the $\mathrm{Na}^{+}$decreased significantly with the increase of mixed salt concentration in all organs, and the ratio of the $\mathrm{K}^{+} / \mathrm{Na}^{+}$in roots was significantly different at various concentrations, but there was no significant difference in the ratio of the $\mathrm{K}^{+} / \mathrm{Na}^{+}$in stems and leaves among multiple treatments. At the same time, the results of this experiment showed that the ratio of the $\mathrm{K}^{+} / \mathrm{Na}^{+}$in roots was less than 1 , while that in stems and leaves was greater than 1 , which indicated that $P$. giganteum mainly regulated ion osmosis under salt stress through roots, thus ensuring the ion balance of aboveground parts, indicating that $P$. giganteum had better physiological regulation mechanism and higher salt tolerance.

\section{Conclusion}

(1) The response mechanism of the growth characteristics of $P$. giganteum to saline-alkali stress is: when the mixed salt concentration is small, the growth of $P$. giganteum plant and the relative water content of the leaves do not decrease significantly, but it decreases with the increase of the salt solution concentration The trend is obvious, that is, high-concentration saline-alkali stress will inhibit the growth of $P$. giganteum.

(2) Under the saline-alkali mixed stress treatment, with the increase of concentration, MDA content accumulated intermittently, $P$. giganteum reduced oxidative damage and maintained normal plant physiological metabolism through the complementary action of antioxidant enzymes SOD and CAT. 
(3) During the mixed saline-alkali stress, when the mixed salt solution concentration is low, the soluble sugar, soluble protein and free proline of $P$. giganteum slowly accumulate, and alternately complete the osmotic adjustment function. As the concentration continues to increase, the free proline content increases rapidly and plays a leading role in the process of osmotic regulation of plants to ensure their physiological activities.

(4) Under mixed saline-alkali stress, $P$. giganteum makes the root and stem absorb most of the $\mathrm{Na}^{+}$, to inhibit its entry into the leaves, and transport $\mathrm{K}^{+}$to the leaves at the same time to ensure its absorption of mineral elements and normal metabolic activities, which is one of the important mechanisms of resistance to mixed stress.

(5) In the future research, the next step will be to analyze the molecular response of $P$. giganteum to saline-alkali stress by new means such as biotechnology and genomics, which will help to provide novel insights into the saline-alkali stress tolerance mechanisms of plant.

Acknowledgements. The study was supported by the Transformation Project of Scientific and technological achievements in Inner Mongolia Autonomous region (CGZH2018137).

\section{REFERENCES}

[1] Amor, N. B., Jimenez, A., Megdiche, W., Lundqvist, M., Sevilla, F., Abdelly, C. (2006): Response of antioxidant systems to $\mathrm{NaCl}$ stress in the halophyte Cakile maritima. Physiologia Plantarum 126(3): 446-457.

[2] Anam, G. B., Reddy, M. S., Ahn, Y. (2019): Characterization of Trichoderma asperellum RM-28 for its sodic/saline-alkali tolerance and plant growth promoting activities to alleviate toxicity of red mud. - The Science of the total environment 662: 462-469.

[3] Ashraf, M., Akram, N. A. (2009): Improving salinity tolerance of plants through conventional breeding and genetic engineering: An analytical comparison. Biotechnology Advances 27(6): 744-752.

[4] Azarin, K. V., Alabushev, A. V., Usatov, A. V., Kostylev, P. I., Kolokolova, N. S., Usatova, O. A. (2016): Effects of salt stress on ion balance at vegetative stage in rice (Oryza sativa L.). - OnLine Journal of Biological Sciences 16(1): 76-81.

[5] Bless, A. E., Colin, F., Crabit, A., Devaux, N., Philippon, O., Follain, S. (2018): Landscape evolution and agricultural land salinization in coastal area: A conceptual model. - The Science of the total environment 625: 647-656.

[6] Bui, E. N. (2013): Soil salinity: A neglected factor in plant ecology and biogeography. Journal of Arid Environments 92: 14-25.

[7] Capula-Rodríguez, R., Valdez-Aguilar, L. A., Cartmill, D. L., Cartmill, A. D., AliaTejacal, I. (2016): Supplementary calcium and potassium improve the response of tomato (Solanum lycopersicum 1.) to simultaneous alkalinity, salinity, and boron stress. Communications in Soil Science and Plant Analysis 47(4): 505-511.

[8] Farooq, M., Gogoi, N., Hussain, M., Barthakur, S., Paul, S., Bharadwaj, N., Migdadi, H. M., Alghamdi, S. S., Siddique, K. H. M. (2017): Effects, tolerance mechanisms and management of salt stress in grain legumes. - Plant Physiology and Biochemistry 118: 199-217.

[9] Guo, R., Shi, L. X., Yan, C. R., Zhong, X. L., Gu, F. X., Liu, Q., Xia, X., Li, H. R. (2017): Ionomic and metabolic responses to neutral salt or alkaline salt stresses in maize (Zea mays L.) seedlings. - Bmc Plant Biology 17(1): 41.

[10] Hayat, K., Zhou, Y. F., Menhas, S., Bundschuh, J., Hayat, S., Ullah, A., Wang, J. C., Chen, X. F., Zhang, D., Zhou, P. (2020): Pennisetum giganteum: An emerging salt 
accumulating/tolerant non-conventional crop for sustainable saline agriculture and simultaneous phytoremediation. - Environmental pollution 265(A): 114876.

[11] Jia, X. M., Wang, H., Svetla, S., Zhu, Y. F., Hu, Y., Cheng, L., Zhao, T., Wang, Y. X. (2019): Comparative physiological responses and adaptive strategies of apple Malus halliana to salt, alkali and saline-alkali stress. - Scientia Horticulturae 245: 154-162.

[12] Jia, X. M., Zhu, Y. F., Zhang, R., Zhu, Z. L., Zhao, T., Cheng, L., Gao, L. Y., Liu, B., Zhang, X. Y., Wang, Y. X. (2020): Ionomic and metabolomic analyses reveal the resistance response mechanism to saline-alkali stress in Malus halliana seedlings. - Plant Physiology and Biochemistry 147: 77-90.

[13] Liang, X. L., Fang, S. M., Ji, W. B., Zheng, D. F. (2015): The positive effects of silicon on rice seedlings under saline-alkali mixed stress. - Communications in Soil Science and Plant Analysis 46(17): 2127-2138.

[14] Liu, B. S., Kang, C. L., Wang, X., Bao, G. Z. (2015): Physiological and morphological responses of Leymus chinensis to saline-alkali stress. - Grassland Science 61(4): 217-226.

[15] Liu, Y. S. (2018): Introduction to land use and rural sustainability in China. - Land Use Policy 74: 1-4.

[16] Lou, Y. H., Guan, R., Sun, M. J., Han, F., He, W., Wang, H., Song, F. P., Cui, X. M., Zhuge, Y. P. (2018): Spermidine application alleviates salinity damage to antioxidant enzyme activity and gene expression in alfalfa. - Ecotoxicology 27(10): 1323-1330.

[17] Ma, H. Y., Liang, Z. W., Yang, H. Y., Huang, L. H., Zhao, M. L. (2011): Ion adaptive mechanisms of Leymus chinensis to saline-alkali stress. - Journal of Food Agriculture and Environment 9(3): 688-692.

[18] Ma, Y. C., Wang, J. Y., Zhong, Y., Geng, F., Cramer, G. R., Cheng, Z. M. (2015): Subfunctionalization of cation/proton antiporter 1 genes in grapevine in response to salt stress in different organs. - Horticulture Research 2(1): 15031.

[19] Maia, J. M., Costa De Macedo, C. E., Voigt, E. L., Freitas, J. B. S., Silveira, J. A. G. (2010): Antioxidative enzymatic protection in leaves of two contrasting cowpea cultivars under salinity. - Biologia Plantarum 54(1): 159-163. (in Chinese with English abstract).

[20] Mambetale, A., Nurbulat, L., Gao, L. L., Zhang, J. S., Tian, L. W. (2017): Effect of salt stress on growth and physiological characteristics of sea island cotton and upland cotton cultivars. - Chinese Bulletin of Botany 52(4): 465-473.

[21] Peng, Y. L., Gao, Z. W., Gao, Y., Liu, G. F., Sheng, L. X., Wang, D. L. (2008): Ecophysiological characteristics of alfalfa seedlings in response to various mixed saltalkaline stresses. - Journal of Integrative Plant Biology 50(1): 29-39.

[22] Rasouli, F., Kiani-Pouya, A. (2015): Photosynthesis capacity and enzymatic defense system as bioindicators of salt tolerance in triticale genotypes. - Flora - Morphology, Distribution, Functional Ecology of Plants 214: 34-43.

[23] Shafqat, N., Ahmed, H., Shehzad, A., Chaudhry, S. K., Shah, S. H., Islam, M., Khan, W., Masood, R., Khan, U. (2019): Screening of wheat-thinopyrum bessarabicum addition and translocation lines for drought tolerance. - Applied Ecology and Environmental Research 17(5): 10445-10461.

[24] Shaheen, H. L., Iqbal, M., Azeem, M., Shahbaz, M., Shehzadi, M. (2016): K-priming positively modulates growth and nutrient status of salt-stressed cotton (Gossypium hirsutum) seedlings. - Archives of Agronomy and Soil Science 62(6): 759-768.

[25] Shi, D. C., Sheng, Y. M. (2005): Effect of various salt-alkaline mixed stress conditions on sunflower seedlings and analysis of their stress factors. - Environmental and Experimental Botany 54(1): 8-21.

[26] Singh, A. (2015): Soil salinization and waterlogging: A threat to environment and agricultural sustainability. - Ecological Indicators 57: 128-130.

[27] Song, T. T., Xu, H. H., Sun, N., Jiang, L., Tian, P., Yong, Y. Y., Yang, W. W., Cai, H., Cui, G. W. (2017): Metabolomic Analysis of Alfalfa (Medicago sativa L.) RootSymbiotic Rhizobia Responses under Alkali Stress. - Frontiers in Plant Science 8: 12081222. 
[28] Yang, C. W., Chong, J. N., Li, C. Y., Kim, C. M., Shi, D. C., Wang, D. L. (2007): Osmotic adjustment and ion balance traits of an alkali resistant halophyte Kochia sieversiana during adaptation to salt and alkali conditions. - Plant and Soil 294(1-2): 263276.

[29] Yang, P. Z., Zhang, P., Li, B., Hu, T. M. (2013): Effect of nodules on dehydration response in alfalfa (Medicago sativa L.). - Environmental and Experimental Botany 86: 29-34.

[30] Zhang, Y. Q., Yang, F., Ren, H. J., Liu, J. L., Mu, W. Y., Wang, Y. (2019): Pseudomonas monteilii $\mathrm{PN}_{1}$ : A great potential $P$-nitrophenol degrader with plant growth promoting traits under drought and saline-alkali stresses. - Biotechnology Letters 41(6): 801-811.

[31] Zhang, H. H., Li, X., Che, Y. H., Wang, Y., Li, M. B., Yang, R. Y., Xu, N., Sun, G. Y. (2020): A study on the effects of salinity and pH on PSII function in mulberry seedling leaves under saline-alkali mixed stress. - Trees 34(3): 693-706.

[32] Zhao, X., Zhu, H. S., Dong, K. H., Li, D. Y. (2017): Plant community and succession in lowland grasslands under saline-alkali conditions with grazing exclusion. - Agronomy Journal 109(5): 2428-2437.

[33] Zhu, Y. F., Jia, X. M., Wu, Y. X., Hu, Y., Cheng, L., Zhao, T., Huang, Z. C., Wang, Y. X. (2020): Quantitative proteomic analysis of Malus halliana exposed to salt-alkali mixed stress reveals alterations in energy metabolism and stress regulation. - Plant Growth Regulation 90(2): 205-222.

[34] Zou, Q. (2000): The guidance of plant physiology experiment. - China Agricultural Press, Beijing. 